\title{
ANALISA REKAYASA NILAI (VALUE ENGINEER) PADA KONSTRUKSI BANGUNAN RUMAH DINAS PUSKESMAS KARANG JATI BALIKPAPAN
}

\author{
Mahyuddin' \\ Program Studi Teknik Sipil, Fakutas Teknik, Universitas Fajar \\ Email: mahyuddin@unifa.ac.id ${ }^{l}$
}

\begin{abstract}
ABSTRAK
Pelaksanaan suatu proyek sangat bergantung pada penggunaan biaya. Dalam kegiatan suatu proyek akan banyak didapati masalah seperti penggunaan material yang boros, tenaga kerja yang kurang terampil dan waktu penyelesaian proyek yang tidak tepat waktu yang menyebabkan pemborosan biaya. Untuk mendapatkan hasil yang efisien dengan menggunakan metode Rekayasa Nilai (Value Engineering). Rekayasa nilai (Value Engineering) adalah suatu pendekatan terorganisasi dan kreatif yang bertujuan untuk mengadakan pengidentifikasian biaya tidak perlu, yang tidak memberikan kualitas atau kegunaan Dengan menggunakan aplikasi rekayasa nilai yang diterapkan pada pekerjaan konstruksi Bangunan Puskesmas Karang Jati Balikpapan dengan mengganti alternative material awal bata merah dengan bata ringan. Besar penghematan keseluruhan pada pekerjaan dinding yang didapat Rp. 50.280 .567 dari biaya awal sebesar Rp. 297.732.062, setelah dilakukan analisis Rekayasa Nilai menjadi Rp. 247.481.470, dengan nilai penghematan sebesar 16,88\%
\end{abstract}

Kata kunci: rekayasa nilai, penghematan, proyek konstruksi, biaya, waktu

\begin{abstract}
Implementation of a project depends heavily on the use of costs. In the activities of a project there will be many problems such as the use of wasteful materials, less skilled labor and insufficient project timing that lead to wasteful costs. To get efficient results by using Value Engineering method. Value engineering is an organized and creative approach aimed at identifying unnecessary costs that do not provide quality or usefulness By using value engineering applications applied to construction work of Puskesmas Karang Jati Building Balikpapan by replacing the alternative of early brick material with brick light. Great overall savings on wall work earned Rp. 50,280,567 from the initial cost of Rp. 297.732.062, after the analysis of Value Engineering to Rp. 247,481,470, with a savings of $16.88 \%$
\end{abstract}

Keywords: value engineering, savings, construction projects, cost, time 


\section{PENDAHULUAN}

Latar Belakang Dalam pembangunan suatu proyek konstruksi pengendalian biaya proyek merupakan hal yang penting dalam proses pengelolaan biaya proyek. Dalam kegiatan suatu proyek akan banyak didapati masalah seperti penggunaan material yang boros, tenaga kerja yang kurang terampil dan waktu penyelesaian proyek yang tidak tepat waktu sehingga menyebabkan pemborosan biaya yang tidak sesuai perencanaan. Dalam manajemen rekayasa konstruksi (MRK) terdapat suatu displin ilmu teknik sipil yang digunakan untuk mengefisienkan biaya. Ilmu tersebut dikenal dengan nama Rekayasa Nilai (Value Engineering)

Rekayasa Nilai (Value Engineering) adalah suatu cara pendekatan yang kreatif dan terencana dengan tujuan untuk mengidentifikasi dan mengefisienkan biaya-biaya yang tidak perlu. Rekayasa nilai (Value Engineering) digunakan untuk mencari alternatif-alternatif atau ideide yang bertujuan untuk menghasilkan biaya yang lebih baik/lebih rendah dari harga yang telah direncanakan sebelumnya dengan batasan fungsional dan mutu pekerjaan Dengan melihat kondisi ekonomi saat ini, maka pada pembangunan proyek yang sedang berjalan yang membutuhkan alokasi dananya cukup besar perlu dipertimbangkan lagi apakah desain yang digunakan telah optimal. Hal ini dapat dilakukan dengan meninjau kembali desain proyek sehingga memungkinkan untuk melakukan peng-hematan biaya dengan cara mengidentifikasi dan mereduksi biaya-biaya yang tidak perlu tanpa mengurangi tingkat mutu, keandalan, serta fungsi proyek itu sendiri.

\section{TINJAUAN PUSTAKA}

Tinjauan Singkat Manajemen Proyek Ciri-ciri proyek adalah:

1. Memiliki tujuan yang khusus, produk akhir atau hasil kerja akhir

2. Jumlah biaya, sasaran dasar serta kriteria mutu dalam proses mencapai tujuan diatas telah ditentukan jelas

3. Bersifat sementara, dalam arti umurnya dibatasi oleh selesainya tugas. Titik awal dan akhir ditentukan jelas

4. Non rutin, tidak berulang-ulang, jenis dan intensitas kegiatan berubah sepanjang proyek berlangsung

Di dalam proses mencapai tujuan telah ditentukan batasan besar yaitu besar biaya (anggaran) yang dialokasikan, jadwal serta mutu yang harus dipenuhi. Ketiga batasan diatas merupakan tiga kendala (triple constraint). Merupakan parameter penting bagi penyelenggara proyek yang sering dialokasikan sebagai sasaran proyek. Tiga kendala tersebut dijabarkan sebagai berikut :

1. Anggaran proyek harus diselesaikan dengan biaya yang tidak melebihi anggaran. Untuk proyek-proyek yang melibatkan dana dalam jumlah besar dan penjadwalan bertahun-tahun, anggaran bukan hanya ditentukan dalam total proyek tetapi dipecahkan bagi komponen-komponennya atau periode tertentu yang jumlahnya disesuaikan dengan keperluan.

2. Jadwal proyek harus disesuaikan dengan kurun waktu dan tanggal akhir yang telah ditentukan. Bila 
hasil akhir proyek baru, maka penyerahannya tidak boleh melewati batas waktu yang telah ditentukan.

3. Mutu, produk atau hasil kegiatan proyek harus memenuhi spesifikasi dan kriteria yang telah dipersyaratkan. Memenuhi persyaratan mutu berarti mampu memenuhi tugas yang dimaksudkan atau sering disebut sebagai fit for the intended use. (Husen, 2011)

\section{Definisi dan Pengertian Rekayasa} Nilai Rekayasa nilai (RN) adalah salah satu teknik manajemen dengan menggunakan pendekatan sistem yang merupakan usaha terorganisir diarahkan pada analisis dan mengidentifikasi fungsi-fungsi yang tidak esensial serta menghilangkan biaya-biaya yang tidak bermanfaat sehingga dicapai fungsi yang diinginkan dengan total biaya yang minimum dengan tetap mempertahankan keamanan (safety), penampilan (performance), keandalan (reliability) dan kualitas (quality) dari produk konstruksi/ proyek. Penerapan rekayasa nilai (RN) dalam industri konstruksi telah menghasilkan penghematan yang besar dan segi material konstruksi, biaya serta waktu. (Sompie, 1993)

\section{Pemilihan Proyek untuk Studi Rekayasa Nilai}

Terbatasnya waktu dan tenaga tidak memungkinkan untuk melakukan studi Rekayasa Nilai secara keseluruhan, kita harus terlatih agar dengan cepat dapat menentukan bagian-bagian mana yang mempunyai potensi besar untuk meningkatkan mutu dan penghematan biaya guna mencapai hasil secara efisien. Dan sebaliknya usaha Rekayasa Nilai pada proyek dirnulai dan tahapan awal konsep dan diteruskan dalam interval dalam Rekayasa Nilai berupa gambar, datadata pendukung selengkap mungkin, dan penentuan tahapan perencanaan pada saat studi dimulai. (Yetty, 2004)

\section{Estimasi Nilai}

Maksud dari estimasi nilai untuk membahas secara singkat metodologi biaya yang tersedia bagi manajer proyek, perencana dan ahli rekayasa nilai. Rekayasa nilai memperoleh nilai terbaik dengan jalan mempelajari ketentuanketentuan yang diperlukan dalarn perancangan (design requirement), menentukan fungsi utama, mengeliminasi bagian-bagian yang tidak diperlukan, mengembangkan alternatif penyelesaian, menentukan biaya siklus hidup untuk mempercepat suatu aktivitas per satuan waktu, yang disebut kemiringan biaya (cost slope).(Mandagi, 2010).

\section{Estimasi Biaya}

Seperti yang sudah dijelaskan oleh J.J.O'Brien "Harga adalah ukuran yang prinsip dalam analisa nilai" Tanpa harga untuk perbandingan analisa nilai akan menjadi subjektif dan konsekuensinya potensi sepenuhnya akan berkurang. Adalah perlu untuk menentukan setiap nilai alternatif menjadi suatu estimasi yang tertentu agar dapat dibandingkan dengan perencanaan yang sebenarnya. Namun pada tahap perencanaan yang dini, dimana potensi penghematan adalah maksimum, banyak bagian yang akan diestimasi belum ditentukan dengan jelas. Hanya setelah perencanaan berjalan jauh dan semuanya telah ditentukan dengan 
mudah dan langsung. ( Mandagi, 2010).

\section{Sistem Estimasi}

Suatu standard sistem atau kerangka kerja untuk mengumpul biaya-biaya adalah penting. Komunikasi diantara anggota perencana, supplier, pelaksana menjadi lebih mudah dan kesalahan-kesalahan dapat dikurangi apabila sistem harga ada standardnya. Kenyataan estimasi biaya dan komputer membutuhkan standar-disasi. Terlepas dari kebutuhannya, walaupun di USA tidak terdapat standard maupun metode dan sistem estimasi. (Mandagi, 2010)

\section{Metode Estimasi}

Prosedur estimasi berbeda-beda dari industri yang satu ke industri yang lain. Banyak pendekatan-pendekatan khusus yang telah dikembangkan antara lain sebagai berikut :

\section{Unit Pemakai/Unit Fungsional}

Fasilitas yang direncanakan atau dibangun ditentukan berdasarkan kapasitasnya seperti misalnya jumlah kendaraan untuk setiap jenis proyek, memerlukan unit perhitungan yang berbeda-beda dalam membuat estimasi biaya. Umpamanya untuk pembangunan jaringan pipa jalan atau terowongan total biaya dapat dipecah menjadi biaya kilometer, jembatan dapat dibagi dalam individual span, pembangkit listrik dapat dipecahkan dalam barrel. Dalam beberapa hal, suatu agen pemakaian yang membangun struktur yang sama berulang-ulang mempunyai suatu data historis yang tersusun dengan baik mengenai harga dan kebutuhan pemakaiannya. Estimasi yang dibuat berdasarkan data semacam ini dapat mendekati akurasi dan presisi.

2. Meter Persegi

Harga-harga meter persegi diperoleh dengan mengalikan luas ruangan yang diperlukan dengan faktor harga yang dibuat baik oleh perencana atau pemilik atau lebih umum dengan menggunakan suatu faktor meter persegi yang dikembangkan oleh organisasi seperti F. W. Dogwe Digest yang memberikan informasi lebih dan 2500 analisis harga untuk 57 jenis bangunan.

\section{Meter Kubik}

Pendekatan ini menyerupai pendekatan meter persegi kecuali ukurannya yang dipakai disini volumenya, sedangkan pada meter persegi adalah luasnya.

4. Estimasi Parameter/Estimasi faktor

Prosedur ini melibatkan penuntun lingkup dari 15-20 subsistem utama yang membuat bangunan itu kemudian menentukan hargaharga pada setiap sistem berdasarkan data historis atau contoh-contoh dan bangunan yang serupa.

\section{Survei Kualitas}

Cara ini yang biasa dipakai oleh Inggris dan Eropa dimana volume dan semua material pada proyek dihitung secara lengkap. Hargaharga pada satuan setiap jenis material dikalikan dengan volumenya masing-masing untuk jumlah harga keseluruhan.(Greinhard, 2011)

METODOLOGI PENELITIAN

Secara garis besar metode yang diterapkan pada analisis Rekayasa 
Nilai Pembangunan Ruko Orlens

Fashion Manado, adalah :
a. Pengumpulan data dan tahapan-tahapan dalam perhitungan (informasi, kreatif, analisa, rekomendasi, dan penyajian ).
b. Pengolahan data.
c. Analisa perancangan penggunaan bahan, dimensi, dan biaya tanpa merubah mutu dan penampilan suatu proyek.
d. Analisa Rekayasa Nilai untuk mengetahui berapa biaya penghematan yang terjadi (cost saving)

Proses Penelitian Langkah-langkah dan hal-hal yang perlu dilakukan dalam proses penelitian, diantaranya

\section{Tahap persiapan}

Sebelum melakukan proses penelitian peneliti harus melakukan tahap persiapan, diantaranya mengumpulkan atau mencari data-data proyek. Setelah mendapatkan data proyek kemudian peneliti melakukan survey ke lokasi proyek untuk mendapatkan gambaran umum kondisi lapangan. Selain itu peneliti juga melakukan studi pustaka baik melalui buku-buku pustaka, internet, maupun bahanbahan lainnya yang dapat dijadikan sebagai bahan referensi dan tambahan pengetahuan.

2. Data penelitian

Data yang digunakan dalam penelitian dikelompokkan menjadi 2, yaitu:

\section{a. Data Primer}

Data primer adalah sumber data yang diperoleh langsung dari sumber asli (dari proyek) / data pokok yang digunakan dalam melakukan analisa Rekayasa Nilai. Data primer dapat berupa data-data teknis dari proyek, seperti gambar dan Rencana Anggaran Biaya (RAB).

\section{b. Data Sekunder}

Data sekunder adalah data-data pendukung yang dapat dijadikan input dan referensi dalam melakukan analisis Rekayasa Nilai. Data sekunder, diantaranya data mengenai daftar harga satuan dan analisa pekerja, data bahan atau material bangunan yang digunakan, data tenaga kerja, dan data-data lainnya yang dapat dijadikan referensi dalam menganalisis Rekayasa Nilai.

3. Metode Pengumpulan Data

Pengumpulan data dapat dilakukan dengan cara:

a. Metode pengambilan data primer

Yaitu metode dengan cara melakukan survey langsung pada konsultan maupun pelaksana yang menangani proyek tersebut. Selain itu peneliti juga melakukan observasi langsung ke lokasi proyek tersebut.

b. Metode pengambilan data sekunder

Yaitu metode dengan cara melaku-kan survey langsung pada instansi-instansi atau perusahaanperusahaan yang dianggap berkepentingan. Perusahaan itu dapat meliputi perusahaan bahan/material ba-ngunan, konsultan, kontraktor, pemborong 
tenaga kerja, instansi yang menangani masalah jasa dan konstruksi bangunan tersebut serta perusahaan-perusahaan lainnya yang bisa dijadikan bahan referensi.

\section{HASIL DAN PEMBAHASAN}

Analisa Biaya Konstruksi Pekerjaan

Pasangan Dinding

$1 \mathrm{~m} 2$ Pasangan Dinding Bata Ringan/Hebel

\begin{tabular}{|c|c|c|c|}
\hline No & $\begin{array}{c}\text { Uraian/koefis } \\
\text { ien }\end{array}$ & $\begin{array}{l}\text { Harga } \\
\text { satuan. }\end{array}$ & $\begin{array}{c}\text { Total } \\
\text { harga( }(\mathrm{Rp} \\
)\end{array}$ \\
\hline \multirow{3}{*}{$\begin{array}{l}1 . \\
2 .\end{array}$} & BAHAN & \multirow{4}{*}{$\begin{array}{l}7500 / b \\
\text { uah } \\
3.550\end{array}$} & \\
\hline & Bata ringan / & & 60.000 \\
\hline & $\begin{array}{l}8 \text { Semen / } \\
1,86\end{array}$ & & 6.603 \\
\hline 1 & TENAGA & & 18.000 \\
\hline 2 & Pekerja / 0.30 & 60000 & 16.000 \\
\hline 3 & Tukang batu / & 80000 & 900 \\
\hline \multirow[t]{3}{*}{4} & 0.20 Kepala & 90000 & \multirow[t]{3}{*}{1.200} \\
\hline & tukang / 0.01 & 85000 & \\
\hline & $\begin{array}{l}\text { Mandor / } \\
0.01\end{array}$ & & \\
\hline & & & 102.7 \\
\hline
\end{tabular}

Analisa Biaya Konstruksi Pekerjaan Plesteran Dinding

\begin{tabular}{|c|c|c|c|}
\hline No & $\begin{array}{c}\text { Uraian/koefis } \\
\text { ien }\end{array}$ & $\begin{array}{l}\text { Harg } \\
\text { a } \\
\text { satu } \\
\text { an. }\end{array}$ & $\begin{array}{c}\text { Total harga } \\
\text { (Rp) }\end{array}$ \\
\hline 1. & $\begin{array}{l}\text { BAHAN } \\
\text { SEMEN MU } \\
\text { / } 10,4\end{array}$ & $\begin{array}{l}1.87 \\
5\end{array}$ & 19500 \\
\hline 1 & TENAGA & & 9.000 \\
\hline 2 & Pekerja / 0.30 & 45.0 & 4.000 \\
\hline 3 & Tukang batu / & 00 & 540 \\
\hline 4 & 0.20 Kepala & 50.0 & 500 \\
\hline
\end{tabular}

\begin{tabular}{|r|l|l|l|}
\hline & tukang / 0.01 & 00 & \\
Mandor / & 60.0 & \\
0.01 & 00 & \\
& & 55.0 & \\
& 00 & \\
\hline \multicolumn{3}{|r|}{ Jumlah } & \\
\hline
\end{tabular}

Perhitungan Rekayasa Nilai Pekerjaan Plesteran Dinding

\begin{tabular}{|l|l|l|l|}
\hline $\begin{array}{l}\text { URAIA } \\
\text { N }\end{array}$ & $\begin{array}{l}\text { QUANT } \\
\text { ITY }\end{array}$ & $\begin{array}{l}\text { Harga } \\
\text { satuan. }\end{array}$ & $\begin{array}{l}\text { Total } \\
\text { harga(Rp) }\end{array}$ \\
\hline $\begin{array}{l}\text { SEMEN } \\
\text { MU }\end{array}$ & $2263 / \mathrm{m} 2$ & 33.950 & $\begin{array}{l}76.032 .29 \\
3\end{array}$ \\
\hline
\end{tabular}

\begin{tabular}{|l|l|l|l|}
\hline No & Uraian/koefisien & $\begin{array}{l}\text { Harga } \\
\text { satuan. }\end{array}$ & $\begin{array}{l}\text { Total } \\
\text { harga(Rp } \\
\text { ) }\end{array}$ \\
\hline 1. & BAHAN & 3.750 & 19.500 \\
& $\begin{array}{l}\text { SEMEN } \\
\text { MU / 2,4 }\end{array}$ & & \\
& TENAGA & 45.000 & 9.000 \\
1 & Pekerja / 0.30 & 50.000 & 4.000 \\
3 & Tukang batu / & 60.000 & 540 \\
4 & 0.20 Kepala & 55.000 & 500 \\
& tukang / 0.01 & & \\
\hline \multicolumn{3}{|c|}{ Mandor / 0.01 } & \\
\hline
\end{tabular}

Sumber: hasil penelitian

Perhitungan Rekayasa Nilai Pekerjaan Acian Dinding

\begin{tabular}{|l|l|l|l|}
\hline URAIAN & QUANT & Harga & Total \\
\hline
\end{tabular}




\begin{tabular}{|l|l|l|l|}
\hline & ITY & satuan. & $\begin{array}{l}\text { harga(Rp } \\
)\end{array}$ \\
\hline $\begin{array}{l}\text { SEMEN } \\
\text { MU }\end{array}$ & $2263 / \mathrm{m} 2$ & 23.040 & $\begin{array}{l}52.150 .5 \\
79\end{array}$ \\
\hline
\end{tabular}

Harga satuan dan total harga dalam rupiah

\section{Sumber Kelayakan}

Dalam kriteria kelayakan terdapat kriteriakriteria sebagai berikut:

\section{Penggunaan teknologi}

- Teknologi yang digunakan sudah biasa atau belum

- Peralatan di lapangan

- Personil di lapangan

2. Biaya pengembangan

- Biaya perencanaan kembali

- Biaya pemesanan kembali/ pembuatan kembali

3. Kemungkinan penyajian

- Kemungkinan diterima oleh pemilik proyek

- Kemungkinan diproduksi di lapa-ngan disesuaikan dengan kemam-puan kontraktor

4. Waktu penyajian

- Waktu perancangan kembali

- Waktu pelaksanaan di lapangan

5. Keuntungan biaya potensial

- Penghematan biaya awal

- Penghematan biaya siklus hidup

Deskripsi Kriteria pada Analisis Matriks Kriteria yang terdapat pada analisa matriks, adalah merupakan saringan dari banyak kriteria yang didaftarkan oleh tim.
Dalam memberikan pembobotan, sebaiknya digunakan "preliminary estimate" sebagai alat bantu. Kriteriakriteria yang ada pada analisis matriks ini mempunyai pengertian sebagai berikut :

1. Keamanan :

- Keamanan struktural

- Keamanan teknis pelaksanaan

2. Biaya awal :

- Biaya konstruksi

3. Biaya operasi dan pemeliharaan :

- Biaya pengoperasian fasilitas

- Biaya perawatan selama siklus hidup

- Biaya penggantian

4. Waktu pelaksanaan :

- Waktu pembuatan

- Waktu di lapangan

5. Kemudahan pelaksanaan :

- Kemudahan pelaksanaan pembuatan

- Kemudahan pelaksanaan di lapa-ngan

6. Potensial penghematan :

- Penghematan biaya awal

- Penghematan biaya siklus hidup

\section{Tahap Pengembangan / Rekomendasi}

Setelah melihat hasil analisis dari tahap analisa maka pada tahap rekomendasi ini, penulis merekomendasikan satu alternatif penggunaan material bata ringan pada pekerjaan pasangan dinding Penghematan biaya pada pekerjaan pasangan dinding:

Dengan menggunakan material awal maka total biaya pekerjaan dinding adalah $\mathrm{Rp}$. 145.864.925,00 bila menggunakan material alternatif bata ringan/hebel maka total biaya pasangan dinding adalah $\mathrm{Rp}$. 132.152.058,00. Terdapat selisih biaya penghematan material alternatif yaitu sebesar Rp. 13.712.867,00. Pada Plesteran dan Acian dengan total biaya awal adalah 
Rp. 146.897.164 dan bila menggunakan material pengganti dengan menggunakan semen mortar utama (MU) maka total biaya menjadi Rp. 123.659.660

\section{Tahap Penyajian}

Penghematan pada pekerjaan pasangan dinding menggunakan bata ringan adalah Rp. 36.956.371

\section{KESIMPULAN}

Dari hasil analisa Rekayasa Nilai pada proyek Pembangunan Rumah Dinas Puskesmas Karang jati, dapat diambil kesimpulan:
1. Untuk item pekerjaan dinding didapat alternatif pengganti yaitu pekerjaan dinding bata merah diganti dengan bata ringan dan untuk pesteran dan acian menggunakan semen mortar utama (MU)

2. Dari alternatif pengganti tersebut diperoleh penghematan secara biaya keseluruhan sebesar Rp 50.280.567 dari biaya awal sebesar Rp. 297.732.062 atau $16,88 \%$.

\section{DAFTAR PUSTAKA}

Ardilla, T., \& N, C. B. 2013. Penerapan Rekayasa Nilai pada Proyek Pembangunan Asrama “ $X$ ” Provinsi Bali, 1(1), 1-8. Bali.

Dwi Ari Ustoyo, 2007. Aplikasi Value Engineering Terhadap Elemen Plat Dan Fondasi Pada Proyek Pembangunan Gedung Rektorat Universitas Muhammadiyah Semarang. Skripsi, fakultas teknik Universitas negeri semarang.

Ganesstri Padma Arianie, Nia Budi Puspitasari, 2017. Perencanaan manajemen Proyek Dalam Meningkatkan Efisiensi dan Efektifitas Sumber Daya Perusahaan (Studi Kasus : Qiscus Pte Ltd), Jurnal Teknik Industri, Undip Semarang.

Hafnidar A. Rani, 2016. Manajemen Proyek Konstruksi, Edisi Pertama, Penerbit DEEPUBLISH, Yogyakarta.

Husen Abrar, 2011. Manajemen Proyek, Edisi Revisi, Penerbit Andi, Yogyakarta.

H. P., \& Utomo, C. 2014. Penerapan Rekayasa Nilai pada Proyek Pembangunan Rumah Tipe 39 di Perumahan Sapphire Park Regency Surabaya, 3(2).

Imam Soeharto, 1999. Manajemen Proyek (dari Konseptual Sampai Operasional), Edisi Kedua, Penerbit Erlangga, Jakarta.

Kembuan, A. S., Tjakra, J., \& Walangitan, D. R. . 2016. Penerapan Value Enginnering pada Proyek Pembangunan Gereja GMIM Syaloom Karombasan, 4(2), 95-103.

Krisnanta Jayawiguna, Anna.R, 2013. Analisa Rekayasa Nilai Pada Pekerjaan Struktur Proyek Gedung PT. Citra Margatama Surabaya, Jurnal Teknik Sipil KERN Vol.3 No.1.Surabaya. 
Labombang, M. 2007. Penerapan Rekayasa Nilai (Value Engineering) pada Konstruksi Bangunan, 5(3), 147-156. Manggala.

Muhammad F.P,Riana.P, 2017. Tahap Informasi, Kreatif, dan Analisa Pada Rekayasa Nilai Untuk Meningkatkan Kualitas Pelayanan Hotel, Industrial Engineering Journal Vo.5 No.2 (2016) 46-51 ISSN 2302 934X, Semarang.

Nur Asty P, 2014. Analisa Value Engineering Pada Proyek Gedung Riset dan Museum Energi dan Mineral Institut Teknologi Bandung, Jurnal Teknik Sipil dan Lingkungan Vol.2, No.1. 2014, Malang.

Pratiwi, N. A. 2014. Analisa Value Engineering pada Proyek Gedung Riset dan Museum Energi dan Mineral Institut Teknologi Bandung, 2(1), 166-170.

Pontoh, M. M., \& Tarore, H. dkk. 2013. Aplikasi Rekayasa Nilai pada Proyek Konstruksi Perumahan (Studi Kasus Perumahan Taman Sari Metropolitan Manado PT. Wika Reality), 1(5).

Priyo, M., \& Hermawan, T. D. 2010. Aplikasi Value Engineering pada Proyek Konstruksi (Studi Kasus : Proyek Pembangunan Gedung BPKP Yogyakarta), 13(2), 116-129.

Rumintang, A. 2008. Analisa Rekayasa Nilai Pekerjaan Struktur Gedung Teknik Informatika UPN “Veteran” Jatim, 4(2), 1-16.

Rompas, A. N. . dkk. 2013. Penerapan Value Engineering pada Proyek Pembangunan Ruko Orlens Fashion Manado, 1(5), 335-340.

Vicky Bertolini, Wsnumurti, Achfas Zacoeb, 2016. Aplikasi Value Engineer Pada Proyek Pembangunan Gedung (Studi Kasus Hotel Grand Barjarmasin), Jurnal IPTEK. Vol. 20 No.2.

Wicaksono, A. Y., \& Utomo, C. 2012. Penerapan Value Engineering pada Pembangunan Proyek Universitas Katolik Widya Mandala Pakuwan City Surabaya, 1(1), 56-62 